\title{
La dictadura de Primo de Rivera. Una oportunidad para la mujer
}

\author{
Paloma Díaz Fernández \\ UNED
}

The Primo de Rivera's dictatorship: An opportunity for women

\begin{abstract}
RESUMEN
ABSTRACT

A través de este antículo se ha tratado de

Through this article we have tried to explicar la importancia de la participación femenina en las instituciones y organismos de carácter político durante la

Dictadura de Primo de Rivera y su significación en la consecución de los derechos políticos plenos de las mujeres en la II República.

PALABRAS CLAVE: Mujer y política, Voto femenino, Dictadura explain the importance of the women's involvement in the institutions and politics organizations during the Dictatorship of Primo de Rivera and how that helped them to get full political rights during the II Republic.

KEYWORDS:

Woman and politics. The woman's vote. Dictatorship of Primo de Rivera.

de Primo de Rivera.

\section{INTRODUCCIÓN}

El 8 de marzo representa un hito en la historia de la emancipación de las mujeres. Esta fecha rememora un luctuoso suceso que tuvo lugar en 1908. Ese año 40.000 costureras industriales se declararon en huelga para reclamar una serie de mejoras como más altos salarios o el derecho a sindicarse. Durante la huelga, 129 trabajadoras murieron quemadas en un incendio en la Cotton Textile Factory, en Washington Square, Nueva York. Al parecer, los dueños de la fábrica habían encerrado a las trabajadoras para forzarlas a permanecer en el trabajo y no unirse a la huelga.

En el año 1910, tuvo lugar la Segunda Conferencia de Mujeres Socialistas en la ciudad de Copenhague, Dinamarca, en ella se estableció el día 8 de marzo como Día Internacional de la Mujer a propuesta de dos miembros del Partido So-
\end{abstract}


cialista Alemán (Clara Zetkin y Kathy Duncker). En España esta fecha representa, no obstante, otro importante hecho en la consecución de los derechos políticos de las mujeres, la concesión del voto. Efectivamente, el 8 de marzo de 1924, el general Primo de Rivera otorgó el voto administrativo a la mujer. ¿Fue casualidad o un reconocimiento implícito el escoger tan señalado día?

Los trabajos realizados sobre el sufragio femenino a partir de la instauración de la democracia son muy numerosos, incrementados de manera notable al celebrarse el cincuentenario de la proclamación de la II República. Sin embargo, el período inmediatamente anterior, el de la Dictadura de Primo de Rivera, apenas se contempla en estos estudios, a pesar de lo importante que fue para el desarrollo del feminismo. En este artículo se pretende una aproximación a uno de los aspectos u objetivos del feminismo, la participación política de la mujer y la obtención del sufragio.

\section{ANTECEDENTES}

El siglo XIX es el siglo de las luchas por el poder de los nuevos grupos sociales surgidos a raíz de la Revolución Industrial. Burgueses primero, proletarios después se sublevan y amotinan en este "siglo de las revoluciones" para alcanzar derechos políticos y libertades. Sin embargo, aunque la presencia de mujeres junto a los hombres en huelgas, motines o barricadas no era infrecuente, los objetivos a conseguir, y en muchos casos conseguidos, no incluian ningún derecho ni libertad para ellas.

Dominadas por una mentalidad tradicional, no sentían la necesidad de dirigir sus esfuerzos a la consecución de unos derechos que les permitiesen igualarse con los hombres. Serían las mujeres burguesas, al igual que había sucedido con los hombres, las primeras en plantearse como objetivo contar con capacidad política. Desde el siglo XVIII las mujeres habian comenzado a actuar en la trastienda de la política. Primero habían sido las aristócratas y sus salones, más tarde las burguesas y sus reuniones de sociedad. Ahora había llegado el momento de dar el paso decisivo e intervenir en la gobernación del país por medio del voto. Sin embargo, y a pesar de que fueron en los países más industrializados donde primero se organizaron las mujeres (Inglaterra y Estados Unidos), éstas no presentaron un bloque unido, interclasista, ya que las obreras no participaron de una forma decidida. La acusación por parte de los partidos y sindicatos obreros de que el voto era un capricho de burguesas retrajo a las trabajadoras concienciadas políticamente a apoyar esta reivindicación.

En España, donde el índice de analfabetismo era altísimo entre las mujeres, el $63,7 \%$ a la altura de 1900 , la lucha sufragista no se dio ni siquiera entre la burguesía. Hubo casos aislados ya en el siglo XIX, considerados más como raros y estrafalarios, que dignos de ser tomados en serio. Así, el 15 de septiembre de 1854, en pleno bienio progresista, un grupo de mujeres, calificadas como «cuatro solte- 
ronas" publicaban un artículo en el diario madrileño La Unión Liberal, donde reivindicaban como primer punto, "El sufragio universal comprensivo de todas las mujeres de probidad "'. El texto también solicitaba la reforma del Código Civil que hasta ese momento concedía la administración de los bienes de la mujer al marido.

No sería hasta el segundo decenio del siglo xx cuando las mujeres, no burguesas sensu stricto ni obreras, sino "capacitadas", abogados, médicos, periodistas, maestras, impulsarían sus reivindicaciones. Sin embargo, la mujer española también tuvo sus defensores dentro de la clase política, desde momentos muy tempranos. Efectivamente, la primera vez que se pensó en conceder a la mujer derechos políticos sería al discutir la Ley Electoral de 1877. El diputado Alejandro Pidal y Mon, líder de los neocatólicos, presentó, junto con otros seis diputados, una enmienda al dictamen de la Comisión sobre el proyecto de ley que restablecía la ley electoral del 18 de julio de 1865. En su escrito se solicitaba el derecho electoral para aquellas mujeres que estuviesen en ejercicio de la patria potestad según la Ley de 20 de junio de 1862 y la de enjuiciamiento civil reformada².

Aunque sólo se solicitaba el sufragio para un grupo muy reducido de mujeres, viudas cabeza de familia y propietarias, era un primer paso, similar a otras iniciativas, como la de los diputados liberales de John Stuart Mill en el Parlamento británico. A pesar de la moderación de la petición y de quien la había propuesto, la enmienda no salió adelante, ya que como se alegó en la contestación no había necesidad de «crear aspiraciones donde dichosamente no existen" ${ }^{3}$. Habrá que esperar treinta años para que de nuevo se proponga el voto para la mujer. La cuestión se suscitará con motivo del debate parlamentario sobre la reforma electoral en junio-julio de 1907. Cuando el proyecto de ley se estaba debatiendo en el Senado se presentaron dos enmiendas, promovida una por un grupo de republicanos, y la otra por el Sr. Palomo, demócrata, a título personal.

La defendida por los republicanos limitaba la posibilidad de votar solo en las elecciones municipales y se concedía el sufragio a las mujeres de 23 años en pleno goce de sus derechos civiles (viudas y solteras emancipadas), con dos años de residencia en el municipio en el que tendría lugar la elección. La enmienda demócrata preveía la posibilidad de votar en todas las elecciones (municipales, provinciales y legislativas), pero solo podrían hacerlo las viudas que satisficieran una contribución territorial no menor de 100 pesetas anuales. Sólo nueve diputados votaron a favor ${ }^{4}$.

1 La Unión Liberal. 15 de septiembre de 1854. DOMENECH, Asunción, «El voto femenino", Historia 16, n. ${ }^{\circ} 163,1985$, p. 22.

2 Diario de Sesiones del Congreso de los Diputados (DSC). 29 de mayo de 1877. Apéndice primero al n. ${ }^{\circ}$ 26. La enmienda iba firmada por Carlos María Perder, José Manuel Díaz Herrera, el Duque de Almenara Alta, Manuel de Azcárraga, Alejandro Pidal y Mon, Eduardo Garrido Estrada y el Marqués de Villalobar.

${ }^{3}$ DSC, 5 de junio de 1877. Fagoaga, C., La voz y el voto de las mujeres. El sufragio en España 1877-1931. Barcelona, Icaria, 1985, pp. 83-92.

4 Diario de Sesiones del Senado (DSS). Presentación de las enmiendas los dias 15 y 16 de julio. Debates de los dias 17, 19, 20 y 23 de julio de 1907. 
Una nueva propuesta se presentará al año siguiente. El 17 de marzo de 1908, cuando se debatía en el Congreso la nueva ley de Régimen de Administración Local, se puso a discusión la enmienda al art. 41 del Proyecto presentada por un republicano, Francisco Pi y Arsuaga, hijo de Pi y Margall. En ella de nuevo se concedía el voto administrativo a las mujeres emancipadas, mayores de edad, y cabezas de familia. La propuesta contó con la firma de seis diputados además de Pi y Arsuaga, ninguno de los cuales luego votaría a favor ${ }^{5}$. La petición fue acogida por los conservadores como revolucionaria; por parte de la izquierda como reaccionaria, la concesión del voto a la mujer supondría entregarlo a la Iglesia. El Gobierno consideraba que no era el momento oportuno, se alegaba que la opinión pública no estaba preparada para otorgar este tipo de privilegios a la mujer.

La enmienda fue derrotada por 64 votos en contra y 35 a favor. Entre los que votaron a favor había republicanos, demócratas, algunos liberales como Moret, Villanueva y Roselló y algunos conservadores ${ }^{6}$. Y es que, como dice Capazzuoli, ni liberales ni conservadores daban un apoyo claro a la concesión del voto femenino ya que temían a este nuevo electorado porque ignoraban quién podría obtener ventajas ${ }^{7}$. Potencial nuevo electorado que por otra parte mostraba una falta prácticamente absoluta de interés por estos temas. Frente a francesas, americanas o inglesas ya plenamente organizadas para defender sus derechos cívicos, las españolas no comenzarán a crear las primeras asociaciones femeninas hasta 1912, con el objetivo prioritario de conseguir derechos laborales.

El año 1918 será un año decisivo para la toma de conciencia de las españolas, para la reivindicación decidida y para la creación de organizaciones en defensa de sus derechos cívicos. La causa fundamental de este salto adelante se encontraba en el aliciente que suponía ver que, después de terminada la Gran Guerra, muchos países habían otorgado derechos políticos a las mujeres como reconocimiento al esfuerzo de guerra por ellas realizado. Surge en este momento en Madrid la Asociación Nacional de Mujeres Españolas (ANME) liderada por María Espinosa. Está integrada entre otras por Clara Campoamor, Elisa Soriano, María de Maeztu, y Victoria Kent. En su primer manifiesto público, A las Mujeres Españolas, encontramos lo que será el objetivo de los grupos sufragistas: igualdad de derechos políticos, jurídicos y económicos. Aparecen otros grupos en diferentes zonas de España. Así, en Valencia la Liga para el Progreso de la Mujer y la Sociedad Concepción Arenal, y en Barcelona La Progresiva Femenina y La Mujer del Porvenir.

Junto a estos grupos cercanos a posiciones de izquierda también aparecen grupos de tendencia católica. La Iglesia, que hasta este momento había rechaza-

5 DSC. La enmienda lleva la fecha de 10 de febrero de 1908, y va firmada por Francisco Pi y Arsuaga, Amadeo Hurtado, Jaime Carner, Juan Garriga y Massó, Rafael Calzada, Juan Caballé y Gocheneche, y José Manuel Pedregal. Apéndice 9.

- DSC, 17 de marzo de 1908.

7 Capezzuol, L. y Cappabianca, G., Historia de la Emancipación Femenina, Madrid, Ed. Miguel Castellote, 1973, pag. 180. 
do la posibilidad de conceder derechos a las mujeres, comienza a darse cuenta de la importancia del movimiento y pretende que éste sea cristiano. Como dice María de Echarri, «El feminismo posible, razonable en España, debe ser netamente católico» ${ }^{8}$. A partir de este momento la defensa del voto de la mujer por parte de $E I$ Debate el periódico católico de la época por antonomasia, será una constante ${ }^{9}$.

El voto femenino constituía, pues, un elemento del debate público cuando el diputado conservador Burgos y Mazo (ministro de Gobernación), uno de los catorce conservadores que había votado a favor de la enmienda de $\mathrm{Pi}$ y Arsuaga en 1908 , presentó el 13 de noviembre de 1919, un nuevo proyecto de ley electoral. En él se otorgaba el voto a todos los españoles de ambos sexos mayores de 25 años que se hallasen en el pleno goce de sus derechos civiles, pero incapacitaba a las mujeres para ser elegibles y establecía dos días para celebrar los comicios, uno para los hombres y otro para las mujeres ${ }^{10}$. La caída del Gobierno supuso que el proyecto no fuese debatido. Sin embargo, Burgos y Mazo había conseguido, en octubre de 1919, que mediante un decreto se reconociese a las mujeres el derecho a ser electoras y elegibles para todos los cargos del Instituto de Reformas Sociales, siendo nombradas a partir de diciembre de ese mismo año tres vocales femeninas, María de Echarri, la marquesa de Rafal y la condesa de San Rafael ${ }^{11 .}$

Será 1919, por tanto, un año importante para impulsar las reivindicaciones femeninas. Curiosamente este impulso se dará sobre todo desde el catolicismo. En este año el Papa Benedicto XV, junto al levantamiento de la prohibición de la participación activa de los católicos en política, dará su aprobación, eso sí de forma velada, al voto femenino. A través de Acción Católica de la Mujer las mujeres católicas comienzan a reivindicar sus derechos civiles y políticos.

En cuanto a la posición de los partidos socialistas en relación con este tema, éstos sólo se preocuparán de la organización sindical de las obreras, descalificando los movimientos feministas por considerarlos burgueses. A pesar de que el Congreso de la Internacional Socialista de Stuttgart de 1907 se declaró partidario de la lucha por el voto femenino, ésta se debía de realizar desde partidos de clase del proletariado, y estos fueron siempre remisos en aceptar los principios de la igualdad entre hombres y mujeres. En el Congreso de Stuttgart los austríacos Victor Adler y Adelheid Popp justificaron su negativa a apoyar el sufragio femenino en aras de una mayor lucha por el sufragio universal de los hombres. Para lograr la conquista de este derecho estimaban conveniente no presentar en el primer plano de la reivindicación también la consecución de derechos electorales para la mujer $^{12}$.

8 DOMÉNECH, A., ob. cit., p. 28.

9 El Debate, 4, 11, 18, y 22 de noviembre de 1918.

${ }^{10}$ DSC, 18 de noviembre de 1919.

11 Blasco Herranz, I., Paradojas de la Ortodoxia. Política de masas y militancia católica femenina en España (1919-1939). Zaragoza, Prensas Universitarias de Zaragoza, 2003, p. 157.

12 HeInen, Jacqueline, De la I a la III Internacional: La cuestión de la mujer, Barcelona, Fontamara, 1978, p. 7. Falcón, Lidia, Mujer y Poder político, Madrid, Vindicación Feminista, 1992, pp. 126-128. 
Así, según nos dice Lidia Falcón, muchas mujeres socialistas se verán de tal manera influidas por un ideario que defienden los hombres socialistas que se convertirán en las peores enemigas del feminismo. Un ejemplo claro lo tendríamos en el debate sobre el sufragio femenino que se dio en las Cortes republicanas entre Victoria Kent y Clara Campoamor. De cualquier forma, los graves sucesos de 1921 y sus posteriores consecuencias hicieron que los pequeños avances conseguidos por las mujeres sufrieran un brusco parón. El momento no era el más idóneo para plantear reformas electorales ni cualquier otro tipo de reivindicaciones. Sería con el Parlamento disuelto, en plena Dictadura de Primo de Rivera, cuando por decisión del Directorio Militar se concedió el voto a la mujer.

\section{3. “DOÑA FULANA DE TAL ;VOTA!»13}

El Estatuto Municipal, promulgado el 8 de marzo de 1924, otorgaba por primera vez el voto a las mujeres. En la Exposición del Decreto-Ley sobre Organización y Administración Municipal, se alegaba que la soberanía municipal reside en el pueblo y debía ser expresada a través del sufragio. Como consecuencia directa de lo anteriormente expuesto se hacía necesario la ampliación del número de votantes, por un lado rebajando la edad de los varones hasta los 23 años, y por otro incluyendo a las mujeres cabeza de familia. Aún más, el nuevo Decreto-Ley no se conformaba con hacer electoras a cierto número de mujeres, también les daba la posibilidad de ser elegibles, es decir, concejales, con el único requisito añadido a los anteriores de ser mayor de 25 años, por lo demás el mismo que se pedía a los hombres ${ }^{14}$.

Esta decisión de otorgar el voto a la mujer se vio de nuevo refrendada el 12 de abril de 1924, cuando la Gaceta de Madrid publica un Real-Decreto para la depuración del Censo Electoral ${ }^{15}$. En la Exposición previa, además de reiterar la concesión del voto a la mujer, se aclaraba la necesidad de depurar el censo con el objetivo de hacer de nuevo a España un Estado constitucional. Completado el censo, y a pesar de las exclusiones, éste arrojaba un total de 6.783 .629 votantes, de los que 1.729 .793 eran mujeres ${ }^{16}$.

La socialista María Cambrils, a pesar de manifestar su insatisfacción por la limitación hecha a las mujeres a la hora de votar, no ocultaba la consideración de logro alcanzado en el avance sufragista ${ }^{17}$. Andrés Saborit, dirigente del PSOE, apreciaba esta concesión hecha a las mujeres como un avance para transformar la

13 España, 22 de marzo de 1924. Editorial titulado «Doña Fulana de tal ¡Vota!» firmado por Azaña. Garcia QueIPo DE Llano, Genoveva, Los intelectuales y la dictadura de Primo de Rivera, Madrid, Alianza Universidad, 1987, p. 47

14 Gaceta de Madrid, 8 de marzo de 1924 . Decreto-Ley, Arts. $51 .^{\circ}$ y $84 .^{\circ}$

15 Gaceta de Madrid, 12 de abril de 1924.

${ }^{16}$ Archivo del Congreso de los Diputados, Sección de Varios, Serie de la Junta Central del Censo o Junta Electoral Central, Legajo 69/2. Octubre de 1924.

17 Cambrils, María, Feminismo Socialista, Valencia, Tipografía Las Artes, 1925, p. 19. 
sociedad capitalista y sugería la necesidad de cambiar la estrategia de dejar al margen el movimiento de redención de la mujer. El socialismo debía de encargarse también de expandir sus ideas entre las mujeres y no consentir que sus reivindicaciones fueran monopolizadas por la Iglesia ${ }^{18}$.

De cualquier forma, la concesión del voto a la mujer se enmarcaba en un plan mucho más ambicioso de reforma de las instituciones, sobre todo las locales. Para llevar esto a efecto, el 24 o 25 de septiembre de 1923 Primo de Rivera habia mantenido una reunión con José Calvo Sotelo, cuyas preocupaciones por el saneamiento electoral eran conocidas por el general. Éste deseaba que el político gallego le pusiera en antecedentes acerca de los estudios que sobre el tema municipal había desarrollado. El proyecto presentado por Calvo Sotelo sobre el nuevo régimen local, anticaciquil y democrático, incluia: representación proporcional, voto de la mujer, supresión de los recursos gubernativos, autonomía municipal plena, desaparición de concejales interinos y alcaldes de Real Orden, Carta municipal... En muchos aspectos existía una coincidencia sustancial con el proyecto de Maura, lógica por otra parte, dado el carácter maurista de su redactor.

En la redacción definitiva del proyecto colaboraron con Calvo Sotelo, a la sazón director general de la Administración; Gil Robles (que redactó lo relativo a la parte electoral); Flores de Lemús (colaboró en la parte relativa a la Hacienda municipal), Vallellano (posteriormente alcalde de Madrid); Jordana de Pozas; Pi y Suñer, y Vidal Guardiola (enviados estos dos últimos por el ayuntamiento de Barcelona). Comentando su propio estatuto, Calvo Sotelo explicaba las razones que le llevaban a pedir la concesión del voto a la mujer. Entre otras la de eliminar la paradoja que se daba ante la posibilidad de que las mujeres pudiesen ocupar cargos públicos y la negación de concederles el acceso a las urnas electorales. Si España concedía el voto a la mujer, sería el primer país latino que rompiera la resistencia a escuchar las reivindicaciones femeninas ${ }^{19}$.

No pudo el autor del proyecto conseguir totalmente sus propósitos. En el Directorio uno de los que más se oponía era el general Vallespinosa, quien alegaba que la mujer que dependía de varón, fuera como esposa o hija, no podía tener derecho a votar. Finalmente, como nos informa Calvo Sotelo, fue ésta opinión la que prevaleció. La extensión del censo electoral que consagraba el Estatuto fue acogida de diferentes maneras. El Debate continuaba dando su apoyo, como venía haciendo desde 1918, y en el editorial del 10 de abril de 1924, dentro del apartado "Lo del Día", destacaba la incorporación de la mujer al nuevo censo electoral, y no sólo esto sino que abogaba por la plena concesión del sufragio femenino aduciendo la injusticia que se cometería si esto no se lograba ${ }^{20}$.

18 Cambrils, María, ob. cit., p. 21.

19 Estatuto Municipal, Decreto-Ley de 8 de marzo de 1924, precedido de un prólogo del Excmo. Sr. Calvo Sotelo, Madrid, Góngora, 1930, p. 7.

20 El Debate, 10 de abril de 1924. 
El Sol también dedicaba un editorial al voto femenino. En él se exponian argumentos pasados y argumentos futuros sobre la eterna "no oportunidad" de conceder el voto a la mujer. Además de señalar el poco interés social que éste tenía y el insignificante movimiento feminista español, añadía la sospecha de que en España los que más insistentemente habian pedido el voto para la mujer habían sido hombres muy calificados de la extrema derecha ${ }^{21}$. El autor de la editorial no debía conocer las iniciativas que a comienzo de siglo habían tenido los republicanos, y cuyas propuestas eran muy similares a las ahora aprobadas, siendo éstas en un punto más progresistas al considerar a la mujer como sujeto elegible.

Como si se quisiera rebatir estos argumentos, al día siguiente apareció en la revista España un editorial con el rotundo encabezamiento "Doña Fulana de tal ¡Vota!»; su autor era Manuel Azaña. Paradójicamente encontramos en el escrito de Azaña argumentos más próximos al periódico católico que al orteguiano El Sol. En el artículo se expresaba la satisfacción por el avance conseguido, si bien consideraba éste algo tímido. En un extenso párrafo defendía la capacidad, igual que la del hombre, de votar de las mujeres. Asimismo consideraba una injusticia argumentar que la supuesta inclinación conservadora del sexo femenino pondría en peligro la libertad. Por un lado razonaba que la mujer tendría una opinión política acorde con el interés de su clase, igual que los hombres, y por otro que el posible refuerzo del conservadurismo gracias al voto de la mujer no era razón suficiente para negarles su derecho ${ }^{22}$.

Esta postura de Azaña, tan clara a favor del voto femenino en 1924 no permanecería en octubre de 1931, cuando en las Cortes Constituyentes de la República se votara a favor del sufragio universal femenino en igualdad de condiciones que el hombre. Su grupo, Acción Republicana, recurriría al tópico de la "no oportunidad" de la concesión a la mujer del voto en aras de la salvación de la República ${ }^{23}$.

En cuanto a las publicaciones feministas, podemos encontrar diferentes posturas también. En la progresista Mundo Femenino, Benita Asas Manterola, presidenta de la ANME, se quejaba ante lo escaso de la propuesta, recordando como ejemplo a las ochenta y seis "diputadas» del Parlamento de Alemania o al número total de "senadoras", cinco, presentes en Europa ${ }^{24}$. Por otra parte Celsia Regis, directora de La Voz de la Mujer, también se quejaba de lo limitado de la concesión, no obstante viera en ella un gran avance sobre todo en comparación con Francia, donde la mujer, a pesar de tener una mayor cultura y estar mucho más organizada

${ }^{21}$ El Sol, 21 de marzo de 1924. Editorial “Acerca del voto femenino", firmado por E. Gómez de Baquero.

${ }^{22}$ España, 22 de marzo de 1924. Editorial titulado "Doña Fulana de tal ¡Vota!» firmado por Manuel Azaña.

${ }^{23}$ Campoamor, Clara, ob. cit, p. 169.

24 SOldevilLa, F., El Año Político 1924, 12 de abril. Madrid, Imp. E. Fernández de Rojas, 1897-1928, (31 vols.). Es de destacar en dicho artículo los neologismos que como tales figuran en el original entre comillas. 
la lucha sufragista, no habia conseguido todavia el voto administrativo, estando éste aprobado por el Congreso, pero detenido en el Senado ${ }^{25}$.

Independientemente de estas diferentes reacciones, el voto estaba concedido y los comicios fueron convocados para el año siguiente, 1925, siendo la mayor incógnita qué posición adoptaria el sexo femenino. El clima antidemocrático en que se iban a desarrollar las elecciones no fue óbice para que tanto la derecha como la izquierda comenzasen pronto su propaganda con vistas a conseguir el voto de las nuevas electoras. Como se ha venido diciendo, la concesión del voto a las mujeres en 1924 no tuvo su traducción práctica, ya que no se celebraron elecciones a pesar del interés manifestado por Calvo Sotelo para que se realizasen. Sin embargo, la renovación de los ayuntamientos comenzada a partir del 1 de abril de 1924 permitió a la mujer desde un primer momento participar activamente en las instituciones municipales, gracias a su nombramiento como concejal e incluso alcaldesa. La novedad que ello suponía nos lo hace ver el que su nombramiento apareciera en titulares en los periódicos:

"Una profesora Concejal Corporativo en Ronda"; "Cuatro concejales femeninos en Segorbe"; "La directora de la Normal, concejal en Málaga"; "Un distrito feminista» 26 .

Se nombraron concejalas a lo largo y ancho de toda la geografía española, tanto en pueblos pequeños como en ciudades (Bilbao, Toledo, San Sebastián, Barcelona, Vigo, Segovia ${ }^{27}$ ), destacando la elección de seis concejalas, tres titulares y tres suplentes, para el ayuntamiento de Madrid. En contra de lo que pudiera pensarse, su labor no creó especial rechazo y aparecía en los periódicos sin mayores críticas que las que pudiera recibir la de cualquier hombre. Y es que muchos de los que pensaban que no habia lugar para la mujer en el gobierno nacional defendian su derecho a intervenir en los asuntos municipales sobre la base de que eran una mera prolongación de los deberes domésticos. Una encuesta realizada por Gregorio Martínez Sierra en 1917 contenía la intencionada pregunta: « ¿No cree usted que la administración municipal es tarea esencialmente femenina? ". La mayor parte de las respuestas fueron afirmativas ${ }^{28}$. Julio Cejador dijo que, al igual que las mujeres mantenian sus casas limpias y arregladas y las decoraban, se encarga-

${ }^{25}$ REgIS, Celsia, La Villa y Corte de España; El Ayuntamiento de Madrid por fuera y por dentro durante la etapa, como Presidente del mismo, del conde de Vallellano, Madrid, Escuela de tipógrafas, 1927, pp. 117 y 118.

${ }_{26}$ El Debate, 9 de abril, 12 de abril, 16 de abril y 26 de noviembre de 1924.

27 Los nombramientos de concejalas en dicho ayuntamientos se puede ver en AHN, sección Fondos Contemporáneos, serie Presidencia de Gobierno, Legajo 369, “Carta del Gobernador Civil de Pontevedra a Primo de Rivera", 1926. Franco RuBIO, Gioria, La incorporación de la mujer a la administración del Estado, municipios y diputaciones 1918-1936. Madrid, Dirección General de Juventud y Promoción Socio-Cultural, 1981, p. 126. Soldevilla, F., El Año Político 1926, 8 de agosto. Madrid, Imp. E. Fernández de Rojas, 1897-1928, (31 vols.).

${ }_{28}$ Las respuestas fueron compendiadas y publicadas por G. Martínez Sierra bajo el título de La mujer moderna, Madrid, 1920, en SCANLON, Geraldine M., La polémica feminista en la España Contemporánea 1868-1974. Madrid, Akal, 1986, p. 153. 
rian de que las calles estuviesen barridas y los jardines limpios; la administración municipal era simplemente la labor doméstica a gran escala ${ }^{29}$.

Otros cargos institucionales para los que fueron nombradas mujeres serían las alcaldías, menos numerosas y en pueblos pequeños, pero a las que accedieron muy tempranamente, así en octubre de 1924 se recibía en Presidencia de Gobierno un telegrama del delegado gubernativo del pueblo de Contretondeta, Alicante, informando del nombramiento como alcaldesa, la primera de España, de doña Maria Pérez Moya ${ }^{30}$. Otras cinco mujeres se sumarian a este restringido grupo ${ }^{31}$. También fueron elegidas algunas mujeres para teniente de alcalde, entre las que destaca, por la importancia de la ciudad, San Sebastián, Carmen Resines ${ }^{32}$.

Para llevar a cabo la regeneración política e institucional que Primo de Rivera pretendía, tan importantes como los municipios lo eran las provincias. Es por ello que, un año después de la promulgación del Estatuto Municipal, se publicaba en La Gaceta un Decreto-ley sobre Organización y Administración Provincial. Este Real Decreto volvía a conceder a la mujer derechos políticos, al darle de nuevo la posibilidad de ser elegible y electora en las elecciones para las diputaciones como se afirmaba en su Exposición ${ }^{33}$. Pero a diferencia de lo ocurrido en los organismos municipales, la mujer apenas tuvo presencia en las diputaciones. Sólo consta un caso, el de Catalina Alastuey, que ocupó un puesto de vocal suplente por la sección de Asociaciones Culturales y de Profesiones Intelectuales en el Consejo Administrativo de Navarra ${ }^{34}$.

Todos estos puestos, tanto en los ayuntamientos como en las diputaciones, fueron ocupados por designación gubernamental delegada en los gobernadores civiles, pues como hemos dicho anteriormente las elecciones nunca se celebraron. Sin embargo, en principio estos nombramientos eran provisionales y se pensaba que terminaría por haber comicios, por lo que las expectativas de voto creadas en el marco de la Dictadura sirvieron para acrecentar la marcha del movimiento feminista.

La Agrupación Femenina Socialista de Madrid convocaba actos dirigidos a las mujeres, generalmente en la Casa del Pueblo, donde invita a hablar a mujeres como Victoria Kent, Clara Campoamor y Matilde Huici, la tres únicas abogadas de Madrid, con objeto de dar a conocer las reivindicaciones de las mujeres. Asimismo, la concejala de Madrid, Consuelo González Ramos, intentaba conseguir el apoyo de las mujeres de tendencias progresistas para pedir el voto integral. Sin embargo,

\footnotetext{
29 Idem, p. 154.

30 SOLDEVILLA, F., ob. cit., 15 de octubre de 1924.

${ }^{31}$ Guerra-Librero Arroyo, G., "Alcaldesas de España", en revista de Estudios de la Vida Local, n. ${ }^{\circ}$ 153. Madrid, 1967, pp. 415-420.

${ }_{32}$ La Voz de la Mujer, 8 de mayo de 1929.

${ }^{33}$ Real Decreto-Ley sobre Organización y Administración Provincial, 20 de marzo de 1925. Gaceta de Madrid, 21 de marzo de 1925.

${ }^{34}$ La Voz de la Mujer, 17 de abril de 1926.
} 
no lo consiguió. En un mitin ofrecido en el teatro Alcázar, el 19 de marzo de 1926, Clara Campoamor excusó su asistencia ${ }^{35}$.

$Y$ es que las feministas españolas, relegaron sus reivindicaciones como tales, priorizando sus ideologías políticas. Esto debilitó en gran medida el movimiento sufragista español. Margarita Nelken, en 1922, comentaba cómo el feminismo católico y el socialista habían colaborado en Europa para conseguir derechos legales y económicos, y citaba como ejemplo el acuerdo de las diputadas del Reichstag alemán para adoptar un frente común en las cuestiones relacionadas con el feminismo. En España, seguía diciendo, a causa de las condiciones de profunda conmoción social vigentes durante la introducción y desarrollo del feminismo éste tenía necesariamente, "un carácter social». Para ella, el feminismo socialista y el feminismo católico no tenian esperanza de entenderse, tenían que ser forzosamente antagónicos ${ }^{36}$. Margarita Nelken señala aquí la razón principal del fracaso feminista español. Las tensiones políticas y sociales en España estaban llegando a un punto que hacia imposible que las feministas de diferentes ideologias encontraran ciertas bases comunes y despojaran a su campaña de todo sectarismo político ${ }^{37}$.

Mientras tanto Primo de Rivera mantenía su apoyo a las mujeres, no sólo en ámbitos políticos, sino también culturales. Así fue cuando en enero de 1927 propone, por primera vez, la candidatura de una mujer, Concha Espina, para ocupar un puesto en la Real Academia de la Lengua. La candidatura de Concha Espina fue duramente atacada, tanto por contar con el apoyo de Primo de Rivera, como por haber obtenido en estas fechas el Premio Nacional de Literatura, en competencia con Ramón Pérez de Ayala, opositor intelectual al régimen. Primo de Rivera, en la carta que dirigió al director de la Academia, Ramón Menéndez Pidal, hizo explícita mención de la capacidad de las mujeres para ser académicas, pero finalmente no fue elegida ${ }^{38}$.

El grado de colaboración de las mujeres comprometidas en la causa feminista con el gobierno de Primo de Rivera fue desigual. Se puede afirmar que no se dio en ningún caso una actitud colectiva. Mientras algunas mujeres rechazaban cargos en los comités paritarios impulsados por Eduardo Aunós - es el caso de Matilde Huici y Clara Campoamor- otras lo aceptaban, como fue el caso de Victoria Kent. De cualquier forma, feministas o no, las mujeres participaron durante la Dictadura siempre que se les brindó la oportunidad. Fue la celebración del plebiscito convocado por la Unión Patriótica la gran prueba que iba a evidenciar hasta qué punto era verdad la pasividad de la mujer en relación con la política activa. El plebiscito se celebró los dias 11,12 y 13 de septiembre de 1926. Su finalidad era sobre todo saber el apoyo con que contaba Primo de Rivera entre los españoles, ante la próxima convocatoria de la Asamblea Nacional, convocatoria que el Rey era renuente a firmar.

\footnotetext{
35 La Voz de la Mujer, 20 de marzo de 1926.

36 Nelken, Margarita, La condición social de la mujer, Barcelona, Minerva, 1922, p. 207.

37 SCANLON, Geraldine M., ob. cit., p. 199.

38 El Heraldo de Madrid, 22 de febrero de 1927.
} 
Hay que manifestar que el interés de la mujer por participar, por primera vez de forma activa, fue evidente desde el primer momento. Ante las numerosas consultas que llegaban a la Unión Patriótica, el comité provincial de Madrid hizo público un anuncio a través del periódico La Nación, animando a todas las mujeres mayores de dieciocho años no sólo a firmar, sino también a ocupar puestos de intervención en las mesas ${ }^{39}$. Al igual que se había hecho campaña entre las mujeres para que estas votaran cuando se promulgó el Estatuto Municipal, ahora también se las animaba a participar en el plebiscito.

La alta participación de la mujer sorprendió a derechas e izquierdas, y cada uno dio su interpretación de este hecho. Para El Sol, a estas alturas claramente opuesto a la Dictadura y punta de lanza de muchos de los intelectuales enfrentados con Primo de Rivera, la explicación de la importante recogida de firmas a favor del régimen tenía como "culpable» la incorporación de la mujer a la vida pública ${ }^{40}$. En el amplio censo electoral que se utilizó para realizar el plebiscito, la mujer suponia el $52 \%$, habiendo firmado de éstas un $40 \%$, porcentaje similar al del hombre $^{41}$. El año político nos da la cifra de 6.694 .164 votantes $^{42}$.

En noviembre de ese mismo año, quizás como premio por la alta participación femenina en el plebiscito, se avanza un paso más en las concesiones políticas que la Dictadura otorga a la mujer. En virtud de Real Orden de la Presidencia, y a pesar de la discrepancia con lo informado por la Junta Central del Censo, se reconoce a la mujer el derecho de figurar y ser incluida en las listas de que tratan los artículos 33 y concordantes de la ley de 8 de agosto de 1907, para que puedan intervenir y formar parte de las mesas electorales ${ }^{43}$. Hay que recordar que cuando se tramitó esta ley ya se había pedido el voto para la mujer, finalmente denegado.

A pesar del éxito del plebiscito transcurrirá un año, septiembre de 1927, hasta que Primo de Rivera consiga su objetivo de la firma del Rey al Real Decreto de convocatoria de la Asamblea Nacional. Siguiendo en su línea de hacer participar a las mujeres, en su art. 15 deja claro quién puede formar parte de ella: "varones y hembras, solteras, viudas o casadas, éstas debidamente autorizadas por sus maridos"44. Cuando se anuncia la convocatoria de una Asamblea Nacional donde quedarían representadas «todas las clases e intereses", la ANME se manifiesta públicamente pidiendo representación, a la vez que reivindica "el voto integral a la mujer y llevando a la misma a las Cámaras Legislativas »45.

39 La Nación, 7 de septiembre de 1926.

40 El Sol, 16 de septiembre de 1926. El Socialista, 15 de septiembre de 1926.

41 Ventura Franch, A., "El voto de las mujeres: un derecho del siglo xx. Estudio histórico y parlamentario del voto femenino en España", en Historia y Derecho. Estudios jurídicos en Homenaje al Profesor Arcadio Garcia Sanz, Valencia, Tirant lo Blanch, 1995, p. 748.

42 SoldeVilla, F., ob. cit. 1926, 13 de septiembre.

43 Idem, 19 de noviembre.

44 Gaceta de Madrid, Asamblea Nacional, Real Decreto-Ley creándola y convocándola y Reglamento provisional de la misma, 12 de septiembre de 1927 y 20 de septiembre de 1927.

${ }_{45}$ Mundo femenino, «Un mensaje al gobierno" articulo firmado por Benita Asas Manterola, n. 39 , diciembre de 1926. 
En la Asamblea Nacional Consultiva, abierta el 11 de octubre de 1927, habia 13 mujeres la mayoría de ellas nombradas como representantes de Actividades de la Vida Nacional, es decir, por destacar dentro de sus profesiones. Natividad Domínguez Atalaya, Micaela Diaz y Rabaneda, María de Maeztu y Whitney, María de Echarri y Martínez, Concepción Loring y Heredia, Carmen Cuesta del Muro, Isidra Quesada y Gutiérrez de los Ríos, Blanca de los Ríos Nostench, María López de Sagrado y Andrés, Teresa Luzzatti Quiñones de López de Rúa, Josefina Olóriz Arcelus, María López Monleón y Trinidad Von Scholtz-Hermensdorff fueron las primeras mujeres que ocuparon escaño en el Congreso español, y aunque la situación no era de normalidad democrática, todas ellas trataron de llevar a debate, de forma seria y estudiada aquellos problemas que consideraban más importantes para la mujer en su momento. Concepción Loring y Heredia fue la primera mujer que habló en el Congreso, hecho que no pasó desapercibido al general, destacándolo en una de sus intervenciones como un momento histórico para el Parlamento y para la intervención de la mujer en la política ${ }^{46}$.

Comenzada ya la primera legislatura fue nombrada María de los Dolores Perales y González Bravo, concejal del ayuntamiento de Madrid. Otras dos mujeres lo serian en la segunda legislatura, María Doménech de Cañellas, presidenta de la Federación Sindical de Obreras, y Clara Frías Cañizares. Hubo otras dos mujeres elegidas para ser asambleístas, Dolores Cebrian y Fernández de Villegas, esposa de Julián Besteiro, y Esperanza García de Torre, esposa de Torcuato Luca de Tena, si bien ambas renunciaron ${ }^{47}$.

A pesar de tener carácter consultivo, la Asamblea elaboró algunos proyectos de ley, entre los cuales destaca el Anteproyecto Constitucional redactado por la sección primera ${ }^{48}$. Dentro del gran número de innovaciones que presentaba a nosotros nos interesa su art. 55, en el que se reconocía el voto político integral para todos los españoles sin distinción de sexos, con la condición de haber cumplido la edad legal y gozar de la plenitud de los derechos civiles "correspondientes al estado de cada cual ${ }^{49}$. Esta última frase, por su ambigüedad, creó una cierta polémica entre Benita Asas Manterola, presidenta de la ANME y directora de su órgano de propaganda, Mundo femenino, y los redactores del Anteproyecto a través de la revista jurídica Justicia ${ }^{50}$. La conclusión a la que llegaron fue que, efectivamente, a la mujer se le había concedido la plenitud del voto y sólo faltaba la aprobación del documento.

46 Diario de Sesiones de la Asamblea Nacional, 23 de noviembre de 1927.

${ }^{47}$ Mas información sobre la labor de las mujeres en la AN pueden encontrarse en las siguientes fuentes: Archivo del Congreso de los Diputados, sección "Documentación Parlamentaria", serie "Documentación Electoral». LaffjtTE, M., Condesa de Campo Alange, ob. cit. pp. 214-216. Blasco HerRANz, I., ob. cit., p. 77.

48 ACD, "Actas de las sesiones de la sección primera", 1927-1929, Legajo 667.

49 ACD, "Anteproyecto de Constitución de la Monarquía Española», elaborado por la Sección primera de la Asamblea Nacional Consultiva, Diario de Sesiones de ANC, n. ${ }^{\circ} 48$, Apéndice $1 .^{\circ}$

so Revista jurídica Justicia, $n .^{\circ} 21,30$ de enero de $1929, n .{ }^{\circ} 43,20$ de septiembre de $1929, n .{ }^{\circ} 46,20$ de octubre de 1929, Mundo Femenino, n. ${ }^{\circ} 61$, octubre de 1929. 


\section{EL AÑO DE 1930}

El 28 de enero de 1930 el General Primo de Rivera presenta su dimisión. A partir de este momento comienza un período de inestabilidad, inquietud y transición, en el que la mujer, de nuevo, volverá a convertirse en ciudadano de segunda. Se trataba de retornar, políticamente hablando, a 1923, olvidando el paréntesis de la Dictadura, como si nada hubiera pasado. Para la mujer también suponía perder todos los avances y conquistas, salir de las instituciones políticas y organismos donde había conseguido entrar, volver a empezar. De los primeros organismos que desaparece es de los ayuntamientos. El 14 de febrero firma el rey Alfonso XIII el Real Decreto que dispone la sustitución de los integrantes de los ayuntamientos y diputaciones designados por la Dictadura. Se hace con carácter transitorio hasta que puedan celebrarse las elecciones municipales. Para la elección de los nuevos alcaldes y diputados provinciales se elige un método mixto, una mitad se elegiría entre los mayores contribuyentes del pueblo, y la otra entre los concejales más votados en las elecciones celebradas entre 1917 y 1923 . A pesar de que este método no facilita, obviamente, la participación de la mujer, todavía podemos encontrar noticias acerca de dos mujeres que fueron elegidas alcaldesas en dos pequeños pueblos de Palencia ${ }^{51}$.

El 15 de febrero de 1930 es disuelta la Asamblea Nacional. Las mujeres que ocupaban escaños vuelven a sus quehaceres habituales, aunque algunas como María de Maeztu pierde no sólo la posibilidad de llevar adelante sus reformas pedagógicas a través de las leyes votadas en la Asamblea, sino también desde su puesto en la directiva de la Junta de Ampliación de Estudios e Investigaciones Científicas, para el que había sido nombrada durante la Dictadura y del que ahora es destituida, a pesar de sus grandes méritos para desempeñarlo.

Las decisiones que el Gobierno había tomado desde el principio y la anunciada revisión de las medidas adoptadas por la Dictadura crearon lógica inquietud entre las mujeres. Fueron varias las que recordaron al Gobierno la necesidad de respetar los derechos que se les había concedido, como el de votar y ser votadas. El mismo día 8 de marzo de 1930, seis años después de la promulgación del Estatuto Municipal, Elisa Soriano demandaba: «Mientras el Estatuto Municipal no se derogue tendremos derecho a votar" ${ }^{52}$. Esta última afirmación hacía referencia al rumor insistente de que pronto se convocarian elecciones. $Y$ es que el gran objetivo del gobierno Berenguer era volver a la normalidad constitucional y para ello se hacía imprescindible celebrar comicios ¿Municipales? ¿Legislativos? ¿Constituyentes? Mientras se resolvía la duda, se procedió a realizar lo más urgente para poder llevar a cabo las votaciones, es decir, la reforma del censo.

51 El Debate, 2 de marzo de 1930.

52 La Mañana, "La doctora Soriano es una entusiasta feminista", artículo firmado por Valentín F. Cuevas, 8 de marzo de 1930. 
La realización del censo se convirtió en un nuevo problema, uno más, para el Gobierno. Éste pretendia mantener el Estatuto Municipal, y por tanto se necesitaba dejar claro quién podría votar en elecciones legislativas y quién en municipales. Sin embargo, pronto se levantaron voces que ponían en duda la legalidad de dicho censo, modificado en 1924 y 1928. El Gobierno, aunque sabía que la confección de un nuevo censo significaría un serio retraso en la celebración de las elecciones, solicitó un informe sobre la creación o rectificación del Censo Electoral a la Junta Central del Censo (JCC). Los debates de la Junta no sólo se centraron en la necesidad de elaborar o no un nuevo censo y en el retraso que esto implicaría, también se evaluó el problema que suponía la inclusión de las mujeres en éste. Se llegó a la conclusión de que era mejor excluirlas, ya que el porcentaje de mujeres que tenían derecho al voto había aumentado considerablemente y ello suponía un problema añadido a la confección del censo ${ }^{53}$.

Desde luego era de destacar que el número de electoras desde el primer censo en que habían estado incluidas, en 1924, se había incrementado de manera notable, pero sobre todo era en algunas capitales de provincias en donde éste era francamente importante. Así, en Madrid suponía el $40,95 \%$, sólo superado por Pamplona con un $40,98 \%$, siendo superior al $30 \%$ en todas las demás capitales de provincia ${ }^{54}$. Con el informe de la JCC en la mano, el Gobierno decidió finalmente elaborar un nuevo censo electoral en el que desaparecian las mujeres, justificando esta medida tanto en la premura para realizarlo, como en su intención de que las primeras elecciones fueran legislativas ${ }^{55}$. No obstante, el Gobierno no descartaba la toma en consideración de las prescripciones de los Estatutos Municipal y Provincial cuando se realizasen, próximamente, elecciones municipales y provinciales.

Finalmente, como se sabe, el 12 de abril de 1931, no se realizaron elecciones legislativas, sino municipales. El Estatuto Municipal no estaba derogado, luego las mujeres tenían que haber votado, tenían derecho. Fue su eliminación del censo lo que se lo impidió. La gran pregunta es, en unas elecciones que cambiaron profundamente el panorama político español, si las mujeres hubieran votado, ¿habria cambiado el resultado de los comicios? ¿habría cambiado la Historia?

\section{CONCLUSIONES}

En los numerosos estudios que se realizan sobre la historia de las mujeres se suele resumir el periodo que abarca la Dictadura de Primo de Rivera como una época estéril en la consecución de derechos. La raquítica concesión del voto que se hizo a la mujer no tuvo ningún efecto al tratarse de un contexto no democrático.

53 ACD, "Actas Junta Central del Censo", Sección de Varios, serie Junta Central del Censo o Junta Electoral Central, Leg. 238B, sesión 5 de abril de 1930, pp. 172-175.

$54 \mathrm{ACD}$, «Resumen, por capitales y provincias, del número de electores que arrojan las renovaciones y rectificaciones del Censo llevadas a cabo en 1924 y 1928 ", Sección Varios, serie JCCE, Leg. 69, n. ${ }^{\circ} 2$.

55 Gaceta de Madrid, 5 de mayo de 1930. 
Sin embargo, en la exposición que hemos hecho en las páginas precedentes ha quedado demostrado que con elecciones o sin ellas la participación de la mujer fue significativa. Su presencia en organismos, instituciones y actos públicos de carácter político produjo un cambio en las mentalidades, incluso en el vocabulario, pues comenzaron a escucharse nuevas palabras como «concejala», "diputada» 0 "aicaldesa".

Hombres y mujeres que, hasta ahora, consideraban un escándalo que la mujer pretendiese algo más que dedicarse a "sus labores" se dieron cuenta de que ésta podía realizar actividades hasta ahora vedadas para ella. Los más reticentes, que a priori debian ser los sectores católicos, no solamente terminaron aceptando esta situación, sino que fueron mayoritariamente sus mujeres las que ocuparon los puestos más significativos.

La evolución que la sociedad española habia experimentado durante la Dictadura en todos los aspectos, económico, social, cultural, político, también alcanzó a la mujer. Del mismo modo que en política no se pudo volver a 1923, la situación de la mujer no se pudo revertir, y su consecuencia fue la aprobación del voto femenino en igualdad con el hombre en las Constituyentes de 1931. 